\title{
Recycling within the Chemical Industry: The Circular Economy Era
}

\author{
Raffaele Cucciniello ${ }^{1, *}$ and Daniele Cespi ${ }^{2, *}$ \\ 1 Department of Chemistry and Biology "Adolfo Zambelli", University of Salerno, Via Giovanni Paolo II 132, \\ 84084 Fisciano, Italy \\ 2 Environmental Management and Consulting (EMC) Innovation Lab S.r.l., Via Nabucco 58, \\ 47922 Rimini, Italy \\ * Correspondence: rcucciniello@unisa.it (R.C.); dcespi@emcinnovation.it (D.C.) \\ Tel.: +39-089-969366 (R.C.); +39-0541-1835510 (D.C.)
}

Received: 6 April 2018; Accepted: 11 May 2018; Published: 19 May 2018

\begin{abstract}
In this present work, we have briefly discussed the importance of recycling within the chemical sector. Recycling is fundamental in promoting a circular economy, which is a new paradigm of sustainability that is able to reduce environmental implications, and in creating new business opportunities. Therefore, to highlight the importance of recycling in the circular economy era, we have reported on some recent examples of strategies helpful to minimize waste by increasing the efficiency of the whole system and promoting a greener/safer chemical industry.
\end{abstract}

Keywords: circular economy; recirculation; green chemistry; green engineering; chemical industry; industrial symbiosis

The new paradigm of a circular economy suggests an innovative way of exploiting resources that is only viable through closed industrial loops. The recovery and recycling of building blocks and semi-finished products guarantee the possibility of exploring new businesses by reducing the environmental burdens due to extraction and refining of virgin materials. This approach can be realized through a new way of thinking, which is based on the waste-to-resource opportunities. As a matter of fact, the core principles of the circular economy involve the recycling and the re-use of materials accompanied by a holistic and sustainable use of resources [1]. Clark et al. [2] introduced a new concept to drive innovation with a sustainable utilization of resources, which they called recirculation. A recirculated product should be returned back to a usable state without becoming waste. By this way, the researchers can maximize material efficiency by reducing pollution and waste.

The chemical industry should represent an excellent example of symbiotic production. According with a well-known quote of August Wilhelm von Hoffman (1848) "in an ideal chemical factory there is, strictly speaking, no waste but only pro-ducts. The better a real factory makes use of its waste, the closer it gets to its ideal, the bigger is the profit". Therefore, the introduction of innovative recycling practices represents a promising opportunity to reduce the overall chemical industry environmental footprint by contributing to the development of a lower carbon society. This crucial point should be stressed when fulfilling the Green Chemistry \& Green Engineering principles [3,4] and pursuing a benign by design [5] production of new chemicals. Although the recycling concept is commonly associated with the end-of-life treatment of such materials, new scenarios that include the recycling of by-products and recovery of solvents in a solvent demanding process represent new emerging goals to achieve. Nowadays, in the circular economy era, waste should represent the feedstock of industrial processes [6] (Figure 1). 


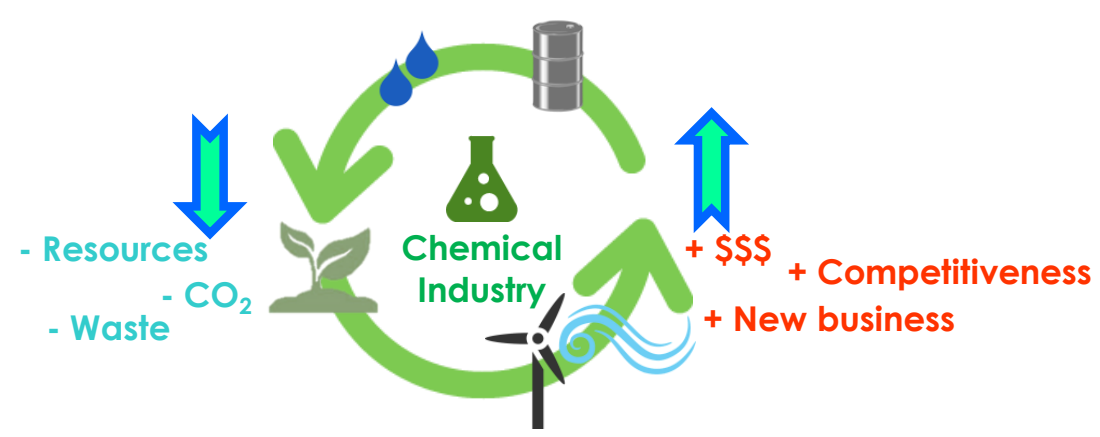

Figure 1. Circular economy era within the chemical industry.

In this context, we recently reported the preparation of high-value compounds, such as monoalkyl glyceryl ethers (MAGEs), using a side-product from the bio-based epichlorohydrin (ECH) synthesis. In more detail, we first evaluated the production of glycidol through a new and highly efficient route, which is based on the conversion of 2-chloro-1,3-propanediol, a by-product in the ECH production chain. After this, we conducted the synthesis of MAGEs by glycidol alcoholysis $[7,8]$. This approach allows us to valorize the entire production chain of bio-ECH by promoting a new valuable and green route for the preparation of glycidol (mainly produced from a fossil-based route that involves the oxidation of alkyl alcohol) and MAGEs.

The carbon dioxide conversion to value-added products has become a major investigated topic. Nowadays, $\mathrm{CO}_{2}$ is mainly produced as a side-product during combustion processes [9]. This research field has attracted increasing interest of the industrial and academic community as it has been estimated that about $5-10 \%$ of the total carbon dioxide emissions can be used to produce fuels and chemicals. From an industrial point of view, the use of carbon dioxide as a starting material could be introduced via key intermediates $\left(\mathrm{CO}, \mathrm{CH}_{3} \mathrm{OH}\right.$, etc.) or as a $\mathrm{C} 1$ building block to reduce fossil dependence and global warming. The main worldwide industrial process that includes $\mathrm{CO}_{2}$ as a starting material is represented by the urea synthesis with an estimated global market of around $250 \mathrm{Mt}$ in 2020 [9]. Furthermore, salicylic acid and polycarbonates can be produced using $\mathrm{CO}_{2}$ as a precursor. Nevertheless, in order to increase the potentiality connected to $\mathrm{CO}_{2}$ recycling, there are two most valuable strategies: (i) its incorporation in fuels rather than chemicals; and (ii) synthesis of materials and products with longer lifespans, such as mineral carbonates that can be used in construction [10]. Using these strategies, it should be possible to create value from $\mathrm{CO}_{2}$ by reducing and preventing emissions as well as allowing companies to be the main actors in a responsible and sustainable new scenario. Centi et al. [11] reported several aspects and opportunities for companies connected to the use of $\mathrm{CO}_{2}$ as a starting material. These included the improvement of the public image of the companies, the reduction of costs for the carbon emissions, the development of new products or processes using a low value compound. More recently, many efforts have been devoted to creating a challenging route based on the $\mathrm{CO}_{2}$ recycling using solar energy [12]. Due to the inherent thermodynamic stability of $\mathrm{CO}_{2}$, many processes demand high energy. Remarkably, the cycloaddition of $\mathrm{CO}_{2}$ to epoxide is thermodynamically favored due to the release of ring-strain energy of the epoxide substrate, with several catalysts favoring the synthesis of cyclic carbonates at an ambient temperature and pressure. The as-obtained cyclic carbonates are generally in liquid form and permits a long-term storage of $\mathrm{CO}_{2}$ [13].

Another crucial aspect that highlights the importance of recycling within the chemical industry is the solvent recovery and reuse in solvent-demanding processes. This practice allows the reduction in the amount of solvent needed for a certain process. Several methodologies have been investigated $[14,15]$. Among these, distillation deserves the majority of the credit, even if this strategy has high-energy demands and accounts for 10-15\% of the world's energy consumption [16]. Capello et al. [17] studied the environmental benefits that are connected to the solvent recovery by distillation with respect to incineration through a detailed life cycle analysis (LCA). The results have shown interesting benefits in terms of avoided environmental impacts related to the production of 
fresh solvents. The importance of solvent recycling and LCA was also discussed in depth in our previous studies $[7,8]$. The LCA results have demonstrated that the avoidance of distillation is not environmentally affordable since greater damages on human health and ecosystems result if no recycling is performed.

In addition to distillation, several alternatives have been investigated and the scientific community is continually looking for new separation techniques that do not rely on heat. One example is organic solvent nanofiltration (OSN), which is mostly used within the pharmaceutical industry [18]. As a matter of fact, the researchers from GlaxoSmithKline have demonstrated that OSN uses 25 times less energy per liter of recovered solvent when compared to distillation [18].

In conclusion, chemistry plays a pivotal role in designing new products with high recyclability or in creating new processes that are able to recycle side-products into valuable molecules/substrates. In this context, an industrial symbiosis approach [19], where the output of one process is the input of another one, can be viewed as an unavoidable solution to fulfil a circular economy by eliminating the primary resource demand [20].

In this short communication, we have reported on some of the recent examples of methodologies that are able to increase the recycling grade within the chemical industry and promote sustainability and new paradigms. The intent is to encourage researchers to share their knowledge on the development of new strategies of separation and recovery of chemical specialties, especially in innovative sectors, such as nanoparticles and bio-based chemicals.

Acknowledgments: This work was financially supported by Fondi di Ateneo per la Ricerca di Base (FARB 2016), University of Salerno (Grant no. ORSA 167988).

Conflicts of Interest: The authors declare no conflict of interest.

\section{References}

1. Clark, J. From waste to wealth using green chemistry: The way to long term stability. Curr. Opin. Green Chem. 2017, 8, 10-13. [CrossRef]

2. Sherwood, J.; Clark, J.H.; Farmer, T.J.; Herrero-Davilla, L.; Moity, L. Recirculation: A new concept to drive innovation in sustainable product design for bio-based products. Molecules 2017, 22, 48. [CrossRef] [PubMed]

3. Anastas, P.T.; Warner, J.C. Green Chem. Theory Pract. 1998; Oxford University Press: New York, NY, USA, 1198.

4. Anastas, P.T.; Zimmerman, J.B. Peer reviewed: Design through the 12 principles of green engineering. Environ. Sci. Technol. 2003, 37, 94-101. [CrossRef]

5. Anastas, P.T.; Ferris, C.A. Benign by Design: Alternative Synthetic Design for Pollution Prevention; American Chemical Society: Washington, DC, USA, 1994; Volume 577.

6. Ricciardi, M.; Cespi, D.; Celentano, M.; Genga, A.; Malitesta, C.; Proto, A.; Capacchione, C.; Cucciniello, R. Bio-propylene glycol as value-added product from Epicerol process. Sustain. Chem. Pharm. 2017, 6, 10-13. [CrossRef]

7. Cucciniello, R.; Ricciardi, M.; Vitiello, R.; Di Serio, M.; Proto, A.; Capacchione, C. Synthesis of monoalkyl glyceryl ethers by ring opening of glycidol with alcohols in the presence of Lewis acids. ChemSusChem 2016, 9, 3262-3265. [CrossRef] [PubMed]

8. Ricciardi, M.; Passarini, F.; Capacchione, C.; Proto, A.; Barrault, J.; Cucciniello, R.; Cespi, D. First attempt of glycidol to monoalkyl glyceryl ethers conversion by acid heterogeneous catalysis: Synthesis and simplified sustainability assessment. ChemSusChem 2018. [CrossRef] [PubMed]

9. Artz, J.; Muller, T.E.; Thenert, K.; Kleinekorte, J.; Meys, R.; Sternberg, A.; Bardow, A.; Leitner, W. Sustainable conversion of carbon dioxide: An integrated review of catalysis and life cycle assessment. Chem. Rev. 2018, 118, 434-504. [CrossRef] [PubMed]

10. Cuéllar-Franca, R.M.; Azapagic, A. Carbon capture, storage and utilization technologies: A critical analysis and comparison of their life cycle environmental impacts. J. CO2 Util. 2015, 9, 82-102. [CrossRef]

11. Antonetti, E.; Iaquaniello, G.; Salladini, A.; Spadaccini, L.; Peranother, S.; Centi, G. Waste to chemicals for a circular economy: The case of urea production (waste-to-urea). ChemSusChem 2017, 10, 912-920. [CrossRef] [PubMed] 
12. Centi, G.; Peranother, S. Opportunities and prospects in the chemical recycling of carbon dioxide to fuels. Catal. Today 2009, 148, 191-205. [CrossRef]

13. Shaikh, R.R.; Pornpraprom, S.; D'Elia, V. Catalytic strategies for the cycloaddition of pure, diluted and waste CO2 to epoxide under ambient conditions. Chem. Rev. 2018, 8, 419-450. [CrossRef]

14. Ricciardi, M.; Passarini, F.; Vassura, I.; Proto, A.; Capacchione, C.; Cucciniello, R.; Cespi, D. Glycidol, a valuable substrate for the synthesis of monoalkyl glyceryl ethers: A simplified life cycle approach. ChemSusChem 2017, 10, 2291-2300. [CrossRef] [PubMed]

15. Cespi, D.; Cucciniello, R.; Ricciardi, M.; Capacchione, C.; Vassura, I.; Passarini, F.; Proto, A. A simplified early stage assessment of process intensification: Glycidol as value added product from epichlorohydrin industry wastes. Green Chem. 2016, 18, 4559-4570. [CrossRef]

16. Sholl, D.S.; Lively, R.P. Seven chemical separations to change the world. Nature 2016, 532, 435-438. [CrossRef] [PubMed]

17. Capello, C.; Fischer, U.; Hungerbuhler, K. What is a green solvent? A comprehensive framework for the environmental assessment of solvents. Green Chem. 2007, 9, 927-934. [CrossRef]

18. Rundquist, E.M.; Pink, C.J.; Livingston, A.J. Organic solvents nanofiltration: A potential alternative to distillation for solvent recovery from crystallization mother liquors. Green Chem. 2012, 14, 2197-2205. [CrossRef]

19. Chertow, M.R. Industrial symbiosis: Literature and taxonomy. Annu. Rev. Environ. Resour. 2000, 25, 313-337.

20. Clark, J.H.; Farmer, T.J.; Herrero-Davilla, L.; Sherwood, J. Circular economy design considerations for research and process development in the chemical sciences. Green Chem. 2016, 18, 3914-3934. [CrossRef]

(C) 2018 by the authors. Licensee MDPI, Basel, Switzerland. This article is an open access article distributed under the terms and conditions of the Creative Commons Attribution (CC BY) license (http:// creativecommons.org/licenses/by/4.0/). 